\title{
PERAN HUTAN TANAMAN RAKYAT DALAM MENINGKATKAN PENDAPATAN DI KESATUAN PENGELOLAAN HUTAN UNIT XIV GEDONG WANI
}

\author{
Role Of Community Plantation Forest In Increasing Income In Forest Management \\ Unit XIV Gedong Wani
}

\author{
Anniza Faradhana*, Susni Herwanti dan Hari Kaskoyo \\ Jurusan Kehutanan Fakultas Pertanian Universitas Lampung \\ JI. Prof. Dr. Soemantri Brojonegoro No.1, Bandar Lampung \\ *Email: Annizafrdhn88@gmail.com
}

\begin{abstract}
Community Plantation Forests (CPF) have a very important role in increasing the income for people around the forest. This study aims to see the role of community plantations is in increasing the farmer's income using Agrosilvopastura cropping pattern. Data collection used observation techniques, interviews, and literature studies. The sampling method used proportional simple random with the number of respondents as many as 90 farmers. Data analysis used income analysis. The results showed that the role of HTR was very influential for the income of farmers $66,25 \%$, compared non CPT $(33,75 \%)$ with an income value of $\mathrm{Rp} 2,258,050,000 / \mathrm{KK} /$ year or $\mathrm{Rp} 8,755,863 / \mathrm{KK} / \mathrm{month}$ using the agrosilvopastura cropping pattern, which was a combination of various agricultural crops $(64,20 \%)$, forestry $(1,36 \%)$, and farm $(0,69 \%)$. Training for farmers and forestry extension workers needs to be carried out to support activities to be more effective and extension workers need to take a more intensive approach to farmers so they can provide solutions and alternative solutions to problems in management.
\end{abstract}

Keywords: Community Plantation Forest; Forest Management Unit; Social Forestry; Agrosilvopastura.

\section{ABSTRAK}

Hutan Tanaman Rakyat (HTR) memberikan peluang bagi masyarakat di dalam atau sekitar hutan untuk meningkatkan pendapatan. Penelitian ini bertujuan untuk melihat peran hutan tanaman rakyat dalam meningkatkan pendapatan petani dengan pola tanam agrosilvopastura. Pengumpulan data menggunakan teknik observasi, wawancara, dan studi literatur. Pengambilan sampel menggunakan proportional simple random dengan jumlah responden sebanyak 90 petani. Data yang sudah dikumpulkan dianalisis pendapatannya yang berasal dari HTR dan non HTR. Hasil penelitian menunjukkan bahwa peran HTR sangat berpengaruh terhadap pendapatan petani sebesar $66,25 \%$ dibandingkan non HTR $(33,75 \%)$ dengan nilai pendapatan $\mathrm{Rp} 2.258 .050 .000 / \mathrm{KK} / \mathrm{tahun}$ atau $\mathrm{Rp}$ 8.755.863/KK/bulan. Pola tanam mengunakan sistem agrosilvopastura yaitu kombinasi antara jenis tanaman pertanian $(64,20 \%)$, kehutanan $(1,36 \%)$, dan petenakan $(0,69 \%)$. Pelatihan untuk petani dan penyuluh kehutanan perlu dilakukan untuk menunjang kegiatan agar lebih efektif; selain itu penyuluh perlu melakukan pendekatan lebih intensif kepada petani sehingga dapat memberikan solusi dan alternatif-alternatif pemecahan masalah dalam pengelolaannya.

Kata kunci: Hutan Tanaman Rakyat; Kesatuan Pengelolaan Hutan; Perhutanan Sosial; Agrosilvopastura. 


\section{PENDAHULUAN}

Hutan memiliki peran penting dalam memberikan manfaat jasa lingkungan dan memberikan manfaat berupa kayu yang memiliki nilai ekonomis tinggi (Agustini et al., 2017). Jumlah penduduk yang semakin meningkat dapat mengakibatkan tingginya permintaan produk hasil hutan sehingga industri-industri perkayuan membutuhkan bahan baku tambahan untuk memenuhi permintaan konsumen. Hutan tanaman perlu dikembangkan sebagai penghasil tambahan bahan baku kayu untuk kebutuhan industri. Herwanti (2015) menyatakan bahwa tanaman kayu di hutan produksi diharapkan mampu memberikan kontribusi untuk memenuhi kebutuhan bahan baku dalam industri perkayuan.

Tingginya permintaan kayu menyebabkan masyarakat membuka lahan hutan sehingga alih fungsi lahan hutan mengalami peningkatan (Alam, 2007). Menurut llham et al. (2016) salah satu upaya yang dilakukan pemerintah Indonesia untuk menjawab permasalahan kehutanan adalah dengan memperbaiki tata kelola sumber daya hutan. Skema pengelolaan hutan berbasis masyarakat diatur dalam Peraturan Menteri Lingkungan Hidup dan Kehutanan Nomor P.83/MENLHK/SETJEN/-KUM.1/10/2016 tentang Perhutanan Sosial salah satunya adalah Hutan Tanaman Rakyat (HTR). HTR adalah hutan tanaman pada hutan produksi yang dibangun oleh masyarakat atau kelompok untuk meningkatkan kualitas dan potensi hutan produksi dengan menerapkan sistem silvikultur sehingga menjamin kelestarian sumber daya serta memberikan kesempatan bagi masyarakat untuk berusaha di bidang hutan tanaman (Herawati et al., 2010). Menurut Kaskoyo et al. (2014); Mulyana et al. (2017); Santoso et al. (2017); Saipurrozi et al. (2018) pelibatan masyarakat dalam pengelolaan hutan negara dapat meminimalkan konflik penggunaan lahan hutan.

Upaya pemerintah meminimalkan kerusakan hutan di Provinsi Lampung dilakukan dengan cara pemberian Izin Pemanfaatan Hasil Hutan Kayu pada Hutan Tanaman Rakyat (IUPHHK-HTR). Salah satu lokasi HTR terdapat di KPH Unit XIV Gedong Wani Register 40 Lampung Selatan. IUPHHK-HTR diberikan pada tahun 2017 dengan luas 30.243 ha dan tersebar di lima desa yaitu Desa Budi Lestari, Desa Sri Katon, Desa Jati Indah, Desa Sinar Ogan, dan Desa Jati Baru (Novayanti et al., 2018). Jenis tanaman yang diusahakan di lahan HTR adalah kombinasi jenis tanaman kehutanan dan tanaman pertanian. Beberapa penelitian menunjukkan bagaimana peran hutan tanaman rakyat terhadap peningkatan pendapatan petani (Sarjono et al., 2017; Miranda et al., 2015). Oleh karena itu penelitian ini penting untuk dilakukan dengan tujuan untuk mengetahui peran HTR dalam meningkatkan pendapatan di KPH XIV Gedong Wani khususnya dengan pola tanam agrosilvopastura.

\section{METODE}

Penelitian dilaksanakan di Desa Budi Lestari dan Desa Sri Katon (Gambar 1) pada bulan Agustus - September 2018. Lokasi ini dipilih karena HTR di KPH Unit XIV Gedong Wani merupakan HTR percontohan di Provinsi Lampung dan kelompok tani hutan yang ada di kedua desa tersebut adalah kelompok tani tertua dibandingkan desa lainnya, serta aktif dalam mengikuti kegiatan. Populasi dalam penelitian ini berjumlah 843 petani yang tersebar di Desa Budi Lestari 410 petani dan Desa Sri Katon 433. Jumlah responden sebanyak 90 petani yang dihitung menggunakan Rumus Slovin (Arikunto, 2011). Metode pengambilan sampel dilakukan secara proportional simple random dengan mempertimbangkan kategori dalam populasi penelitian. Hal ini karena Desa Budi Lestari dan Sri Katon memiliki jumlah sub populasi yang tidak sama, sehingga didapatkan 44 responden di Desa Budi Lestari dan 46 responden di Desa Sri Katon. 


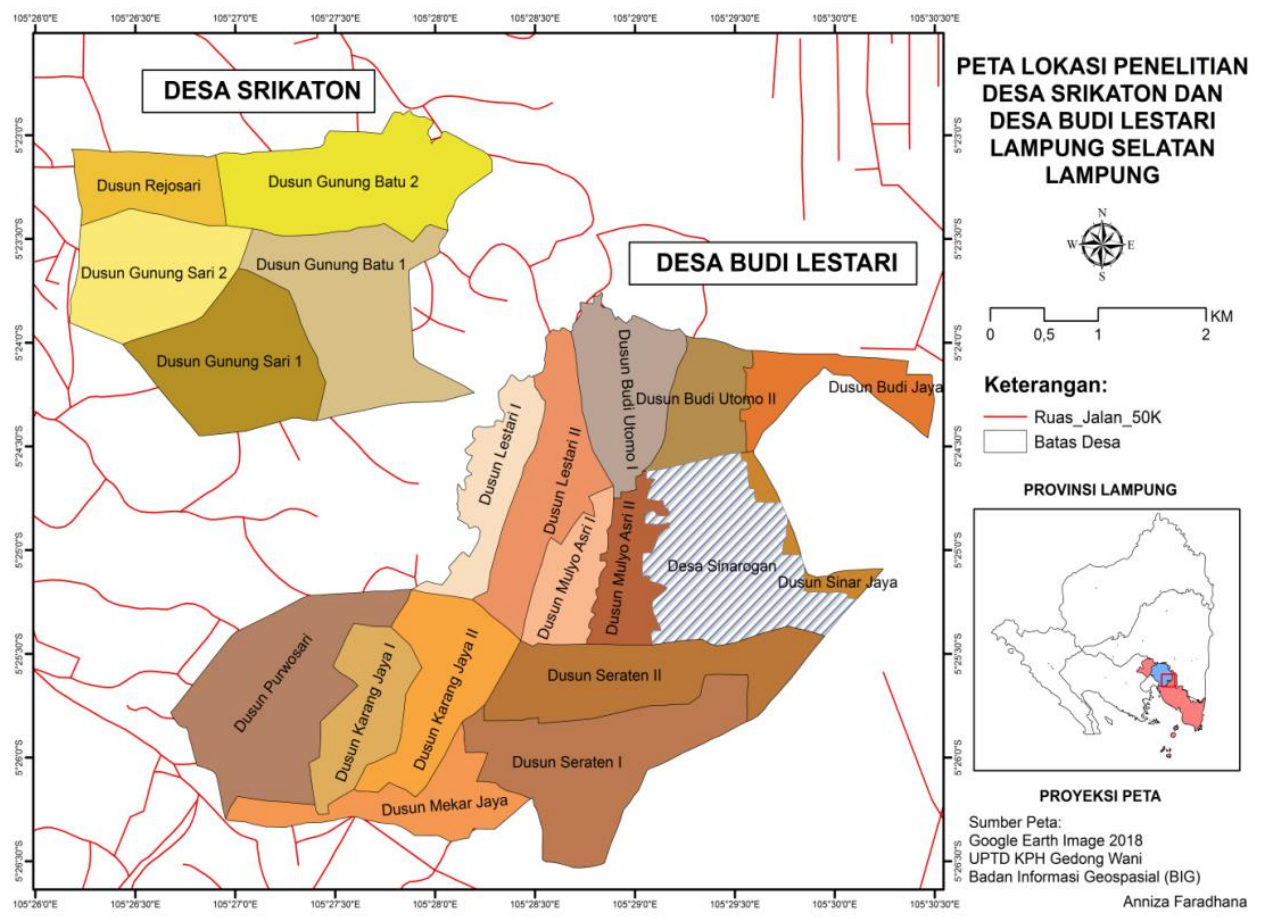

Gambar 1. Lokasi Penelitian

Figure 1. Research Sites

Alat yang digunakan adalah alat tulis, daftar pertanyaan (kuisioner), kamera digital, dan laptop. Jenis data yang dikumpulkan data primer dan data skunder. Data primer meliputi nama petani, jumlah tenaga kerja, luas lahan, tingkat pendidikan, umur, jumlah tanggungan keluarga, jenis kelamin, dan jenis tanaman. Data sekunder meliputi data jumlah penduduk, data luas lahan, data pekerjaan, dan studi literatur. Analisis data menggunakan rumus pendapatan (Soekartawi, 1995):

$$
\mathrm{Pd}=\mathrm{TR}-\mathrm{TC}
$$

$$
\begin{aligned}
& \text { Keterangan : } \mathrm{Pd}=\text { Total Pendapatan } \\
& \mathrm{TR}=\text { Total Peneriman } \\
& \mathrm{TC}=\text { Total Biaya }
\end{aligned}
$$

\section{HASIL dan PEMBAHASAN}

\section{A. Kondisi Umum Lokasi}

Kesatuan Pengelolaan Hutan (KPH) XIV Gedong Wani terletak di dua Kabupaten yaitu Kabupaten Lampung Selatan dan Kabupaten Lampung Timur. IUPHHK-HTR diberikan pada tahun 2017 dengan ketetapan luas wilayah sebesar 30.243 ha. Penggunaan lahan meliputi pemukiman $(7,6 \%)$, pabrik $(0,28 \%)$, perkebunan $(0,91 \%)$, pertanian lahan kering $(70,6 \%)$, lahan terbuka $(6,79 \%)$, belukar $(1,02 \%)$, dan kebun campuran $(12,8 \%)$ (KPHP Gedong Wani, 2015).

HTR merupakan program pembangunan yang strategis dalam upaya peningkatan produksi kayu sehingga dapat meningkatkan kesejahteraan masyarakat di sekitar kawasan hutan melalui adanya pembentukan kelompok tani hutan. Kelompok tani hutan di Desa Budi Lestari bernama Wana Lestari dan di Desa Srikaton bernama Jaya Abadi. Pembentukan kelompok tani hutan mampu mempermudah petani untuk mendapatkan informasi terkait HTR serta bantuan berupa bibit dan pupuk dari pemerintah daerah. 
Pola tanam yang digunakan petani dalam mengelola lahan HTR adalah sistem agrosilvopastura yaitu kombinasi antara jenis tanaman pertanian, kehutanan, dan peternakan. Jenis tanaman pertanian terdiri dari padi, jagung, dan singkong sedangkan jenis tanaman kehutanan meliputi karet, sengon, akasia, dan mahoni serta jenis hewan yang diternak oleh petani adalah sapi dan kambing.

\section{B. Pendapatan Petani HTR}

Tanaman karet memberikan pendapatan paling besar yaitu $\mathrm{Rp} 27.022 .400 / \mathrm{KK} / \mathrm{tahun}$. Harga jual getahnya saat ini Rp $6.000 / \mathrm{kg}$. Harga tersebut naik dibandingkan harga sebelumnya sekitar Rp 4.000/kg. Petani biasanya melakukan penyadapan batang karet setiap hari lalu dikumpulkan dan jika sudah terkumpul dalam seminggu karet akan dijual ke pengepul. Petani HTR beranggapan bahwa tanaman karet memiliki usia produktif lebih lama, sehingga dapat terus dipanen tanpa harus mengganti tanaman karet yang baru. Umur pohon karet di kedua desa ini kisaran 3,5-15 tahun dan sudah siap sadap pada umur 3,5-4 tahun. Senada dengan penelitian yang dilakukan Pusari \& Haryati (2014) bahwa batang pohon karet yang sudah siap sadap di kisaran umur 3,5-5 tahun. Menurut Hadi \& Rifai (2014) tanaman karet memberikan sumbangan pendapatan yang cukup besar terhadap pendapatan petani sebesar Rp 54.235.729/KK/tahun.

Komoditi padi memberikan pendapatan terbesar kedua setelah karet yaitu $\mathrm{Rp}$ 22.461.538/KK/tahun. Frekuensi penanaman padi dalam setahun sebanyak dua kali yaitu pada musim hujan dan kemarau dengan umur masa tanam empat bulan. Petani menjual hasil panen berupa beras dengan harga jual beras kisaran $\mathrm{Rp} 3.500-\mathrm{Rp} 5.000$. Harga ini ditentukan berdasarkan kualitas beras itu sendiri dan pemberian pupuk NPK oleh petani pada musim tanam. Asnawi (2013) menyatakan semakin tinggi pupuk NPK yang digunakan maka akan semakin tinggi hasil produksi padi. Hasil penelitian ini menunjukkan kesamaan dengan Prasetyo et al. (2016) bahwa tanaman padi masih menjadi sumber pendapatan petani karena tanaman padi memberikan sumbangan yang cukup besar untuk memenuhi kebutuhan pangan.

Komoditi singkong memberikan pendapatan sebesar $\mathrm{Rp} 21.980 .000 / \mathrm{KK} / \mathrm{tahun}$ dengan frekuensi panen satu kali dalam setahun. Harga jual singkong yaitu $R p$ 900-Rp $1.000 / \mathrm{kg}$. Petani mengakui harga singkong saat ini naik dibandingkan dengan harga awal

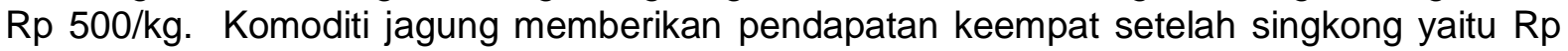
20.500.000/KK/tahun dengan frekuensi panen sebanyak dua kali dalam setahun dan harga jual jagung yaitu Rp 2.000-Rp 3.000/kg. Petani HTR mempertahankan komoditi singkong dan jagung karena menurut petani kedua komoditi tersebut sangat mudah dipasarkan dan lebih cepat panennya.

Tanaman jengkol dan kelapa hanya sebagai tanaman pengisi di antara jagung dan singkong. Hasil panen jengkol dan kelapa sebagian besar dijual dengan sistem borongan untuk 20 pohon tanaman jengkol dipatok dengan harga Rp 1.500.000/borongan, sedangkan untuk 20 tanaman kelapa dipatok dengan harga Rp 800.000/borongan. Kedua komoditi ini juga biasanya dikomsumsi sendiri oleh petani dan dibagikan oleh tetangga atau kerabat terdekat karena tidak semua petani menanam dua komoditi tersebut.

Sebagian besar petani menanam tanaman pertanian yaitu padi, jagung, singkong, dan karet, karena menurut petani umur panen yang singkat lebih menguntungkan dibandingkan tanaman pohon yang umur panennya lebih lama yang mencapai 5 tahun. Tanaman kehutanan seperti akasia, mahoni, dan sengon ditanam oleh sebagian kecil petani; karena tanaman tersebut hanya sebagai tanaman pengisi. Menurut Erwin et al. (2017); Febryano et al. (2009) salah satu pertimbangan petani dalam memilih jenis tanaman adalah waktu panen yang singkat.

Petani di kedua desa ini menjual seluruh hasil panen ke pengepul. Pengepul merupakan pedagang yang membeli komoditas hasil panen dari petani dan memasarkan dengan harga yang murah di bawah harga pasaran. Sebagian besar petani hanya menunggu pengepul mendatangi rumah petani untuk membeli hasil panen karena menurut 
petani jika petani mengantarkan hasil panen ke pengepul maka petani akan mengeluarkan biaya tambahan untuk transportasi. Kholifah et al. (2017) menyatakan bahwa petani tidak ingin repot dan mengeluarkan biaya lagi untuk menghantarkan hasil panen ke pengepul.

Ternak yang dimiliki petani hanya dua jenis yaitu kambing dan sapi, rata-rata petani memiliki 3 ekor kambing dan 1 ekor sapi. Pakan ternak yang biasanya diberikan petani merupakan rumput yang berasal dari lahan HTR. Petani HTR tidak memiliki jumlah ternak yang terlalu banyak karena menurut petani jika jumlah ternak terlalu banyak petani takut kesusahan dalam mengurusnya dan memberi makan. Pendapatan dari peternakan terbilang kecil karena petani menjual hasil ternak hanya pada musim- musim tertentu seperti hari raya besar. Hasil penelitian ini sejalan dengan Persetyo et al. (2016) pendapatan dari peternakan hanya menjadi sumber pendapatan pendamping.

Luas lahan garapan petani rata-rata 1,5 ha dengan kisaran $0,5-4$ ha. Semakin luas lahan garapan petani semakin besar pula pendapatan petani. Penelitian Susanti \& Rauf (2013) menunjukkan luas lahan garapan petani mempengaruhi pendapatan. Susilowati dan Maulana (2012) menambahkan bahwa luas lahan 0,5-1 ha sudah mencukupi untuk memenuhi kebutuhan petani..

Petani menggunakan tenaga kerja pada saat musim tanam dan musim panen berlangsung. Hasil penelitian ini menunjukkan bahwa rata-rata tenaga kerja yang digunakan oleh petani adalah satu hingga dua orang dan tidak semua petani menggunakan tenaga kerja. Petani yang menggunakan tenaga kerja dipengaruhi oleh kepemilikan luas lahan yang besar, sehingga dengan adanya tenaga kerja tambahan maka proses penanaman dan pemanenan tidak memerlukan waktu yang lama. Hasil penelitian memiliki kesamaan dengan penelitian yang dilakukan oleh Mariani et al. (2011) bahwa jumlah tenaga kerja berpengaruh nyata terhadap pendapatan petani.

Pendapatan non HTR merupakan pendapatan yang didapatkan di luar kegiatan pertanian 33,75 \% (Gambar 2). Jenis pekerjaan buruh pabrik memberikan sumbangan sebesar Rp 18.240.000/KK/tahun, sedangkan buruh bangunan Rp 3.171.429/KK/tahun. Alasan petani bekerja sebagai buruh pabrik dan buruh bangunan yaitu untuk memberikan tambahan pendapatan serta jarak tempuh pabrik tidak jauh dengan rumah petani. Usaha warung di kedua desa ini sebanyak tujuh warung yang memberikan pendapatan sebesar Rp 11.007.143/KK/tahun. Pendapatan dari pekerjaan tukang ojek adalah sebesar Rp $1.800 .000 / \mathrm{KK} / \mathrm{tahun}$. Pekerjaan ojek di kedua desa ini sebagai ojek antar jemput anak sekolah, karena jarak tempuh rumah ke sekolah relatif jauh. Pendapatan dari pekerjaan sebagai aparat desa sebesar $\mathrm{Rp}$ 14.400.000/KK/tahun sedangkan pendapatan dari pekerjaan buruh tani adalah $\mathrm{Rp} 240.000 / \mathrm{KK} /$ tahun. Pekerjaan sebagai buruh tani merupakan pekerjaan yang tersedia pada saat musim tanam dan musim panen berlangsung.

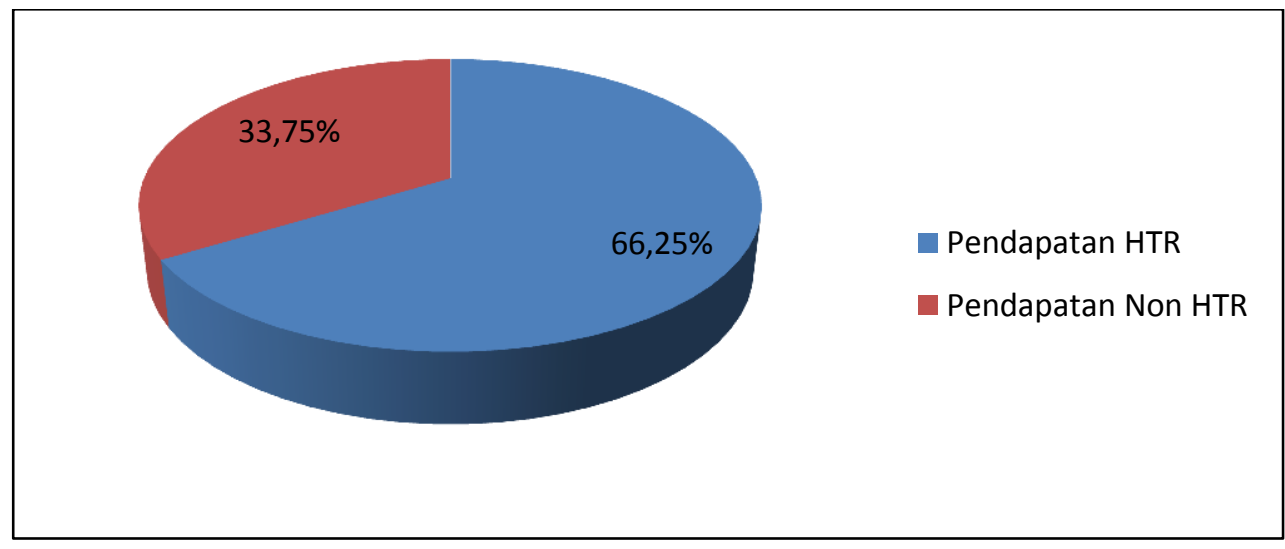

Gambar 2. Pendapatan petani dari HTR dan non HTR

Figure 2. Farmer income from CPF and non CPF 


\section{Peran HTR dalam Meningkatkan Pendapatan}

Tanaman budidaya tahunan berupa kayu hanya memberikan pendapatan sebesar $1,36 \%$ dari sumber pendapatan HTR, sedangkan tanaman pertanian sebesar $64,20 \%$ dan peternakan sebesar 0,69\% (Gambar3). Sebagian besar petani memilih menanam tanaman pertanian dibandingkan tanaman kehutanan untuk meningkatkan pendapatan karena petani beranggapan bahwa tanaman pertanian lebih cepat dipanen dan menghasilkan pendapatan dibandingkan tanaman kehutanan. Hasil ini tidak sesuai dengan Peraturan Menteri Kehutanan No.P.55/Menhut-II/2011 tentang Pemanfaatan Hasil Hutan Kayu dalam Hutan Tanaman Rakyat.

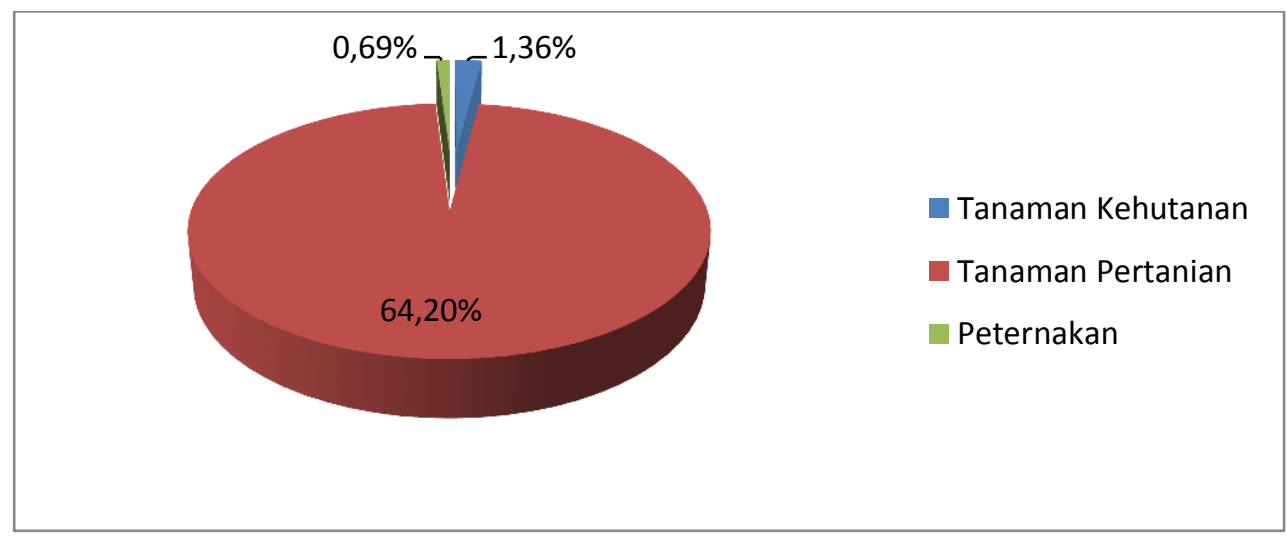

Gambar 3. Pendapatan petani dari HTR berdasarkan jenis komoditas Figure 3. Farmer income from CFP is based on commodity type

Permasalahan yang dihadapi dalam pengelolaan IUPHHK-HTR Gedong Wani yaitu kurangnya pemahaman petani dalam program HTR serta pengelolaan aspek silvikultur yang masih kurang baik. Pemahaman petani yang sudah lama menetap untuk membuka kawasan hutan menjadi lahan pertanian dan adanya dukungan dari sektor pertanian membuat konsep HTR kurang diterima oleh petani. Pada umumnya, petani menginginkan agar kawasan yang dikelola menjadi hak milik pribadi melalui suatu proses pelepasan kawasan hutan. Hal ini menyebabkan masyarakat tidak mau terlibat atau berpartisipasi dalam kegiatan HTR. Sejak diturunkan IUPHHK-HTR kegiatan sosialisasi yang telah dilakukan oleh penyuluh maupun instansi terkait lainnya kepada petani belum efektif. Hasil penelitian ini serupa dengan penelitian yang dilakukan Novayanti et al. (2018) bahwa kurangnya tenaga pendamping dan rendahnya intensitas sosialisasi di KPH Unit XIV Gedong Wani menyebabkan pengetahuan masyarakat terhadap program pembangunan HTR rendah dan saat ini, penyuluh yang berjalan baru bersifat teknis.

\section{KESIMPULAN dan SARAN}

Peran hutan tanaman rakyat dengan pola tanam agrosilvopastura sangat besar dalam meningkatkan pendapatan. Hasil pendapatan petani di lahan HTR lebih besar $(66,25 \%)$ dibandingkan non HTR $(33,75 \%)$. Nilai total Rp 2.258.050.000/KK/tahun atau sebesar Rp 8.755.863/kk/bulan. Jenis tanaman kayu di lahan HTR menunjukan persentase yang sangat kecil $(1,36 \%)$ dibandingkan dengan tanaman pertanian yaitu sebesar $(64,20 \%)$ dari pendapatan total HTR. Pendampingan dan sosialisasi perlu dilakukan secara intensif oleh penyuluh kehutanan kepada petani tentang fungsi utama HTR dan dapat memberikan solusi alternatif-alternatif pemecahan masalah dalam pengelolaannya. 


\section{DAFTAR PUSTAKA}

Agustini, S., Dharmawan, A.H. \& Putri, E. I.K. (2017). Kontribusi hutan nagari pada struktur nafkah dan ekonomi pedesaan: Studi kasus di Padang Pariaman. Sodality, 5(2), 138147.

Alam, S. (2007). Hubungan kondisi sosial ekonomi masyarakat dengan konversi hutan rakyat menjadi areal perladangan berpindah (Studi kasus petani hutan kemiri rakyat Kabupaten Maros). Jurnal Hutan dan Masyarakat, 2(3), 280-290.

Arikunto, S. (2011). Prosedur Penelitian Suatu Pendekatan Praktik. Jakarta: Rineka Cipta.

Asnawi, R. (2013). Analisis faktor-faktor yang mempengaruhi produksi padi sawah inbriding dan hibrida di Provinsi Lampung. SEPA, 10(1),11-18.

Erwin., Bintoro, A. \& Rusita. (2017). Keragaman vegetasi di Blok Pemanfaatan Hutan Pendidikan Konservasi Terpadu (HPKT) Tahura Wan Abdul Rachman, Provinsi Lampung. Jurnal Sylva Lestari, 5(3), 1-11. doi: 10.23960/jsl351-11.

Febryano, I.G., Suharjito, D. \& Soedomo, S. (2009). Pengambilan keputusan pemilihan jenis tanaman dan pola tanam di lahan hutan negara dan lahan milik: Studi kasus di Desa

Sungai Langka, Kecamatan Gedong Tataan, Kabupaten Pesawaran, Provinsi Lampung. Forum Pascasarjana, 32(2), 129-141.

Hadi, S. \& Rifai, A. (2014). Analisis kemampuan membayar pinjaman oleh petani pada eks proyek UPP Perkebunan Tree Crops Smallholder Delevopment Project (TCSDP). Jurnal of Agricultural Economics, 5(1), 35-51.

Herawati, T., Widjayanto, N., Suharudin \& Eriyanto. (2010). Analisis responden pemangku kepentingan di daerah terhadap kebijakan hutan tanaman rakyat. Jurnal Analisis Kebijakan Kehutanan, 7(1), 13-25.

Herwanti, S. (2015). Potensi kayu rakyat pada kebun campuran di Desa Pesawaran Indah Kabupaten Pesawaran. Jurnal Sylva Lestari, 3(1), 113-120. doi: 10.23960/jsl13113120.

Ilham, P. Q., Purnomo, H. \& Nugroho, T. (2016). Analisis pemangku kepentingan dan jaringan sosial menuju pengelolaan multipihak di Kabupaten Solok, Sumatra Barat. Jurnal IImu Pertanian Indonesia, 21(2), 144-149. doi: 10.18343/jipi.21.2.114.

Kaskoyo, H., Mohammed, A. \& Inoue, M. (2014). Present state of community forestry (Hutan Kemasyarakatan /HKM) program in a protection forest and its challenges: Case study in Lampung Province, Indonesia. Journal of Forest Science, 30(1), 15-29.

Kholifah, U. N., Wulandari, C., Santoso, T. \& Kaskoyo, H. (2017). Kontribusi agroforestri terhadap pendapatan petani di Kelurahan Sumber Agung Kecamatan Kemiling Kota Bandar Lampung. Jurnal Sylva Lestari, 5(2), 39-47. doi: 10.23960/jsl3539-47.

Kesatuan Pengelolaan Hutan Produksi Gedong Wani. (2015). Rencana Pengelolaan Hutan Jangka Panjang. Bandar Lampung: KPHP Gedong Wani.

Mariani., Maryam, S. \& Husinsyah. (2011). Pengaruh metode System of Rice Intensification (SRI) terhadap pendapatan dan efisiensi usaha tani (Oryza sativa) di Desa Karang Tunggal Kecamatan Tanggorang Seberang Kabupaten Kutai Lartanegara. Jurnal Agribisnis, 8(2), 17-23.

Miranda, A., Lumangkun, A. \& Husnani, A. (2015). Analisa pendapatan petani karet dari hutan tanaman rakyat di Trans SP 1 Desa Pangmilang Kecamatan Singkawang Selatan Kota Singkawang Kalimantan Barat. Jurnal Hutan Lestari, 3(4), 517-525.

Mulyana, L., Febryano, I.G., Safe'i, R. \& Banuwa, I. R. (2017). Performa penelolaan agroforestri di wilayah Kesatuan Pengelolaan Hutan Lindung Rajabasa. Jurnal Hutan Tropis, 5(2), 127-133.

Novayanti, D., Banuwa, I. S., Safe'i, R., Wulandari, C. \& Febryano, I. G. (2018). Analisis faktor-faktor yang mempengaruhi persepsi masyarakat dalam pembangunan hutan 
tanaman rakyat pada KPH Gedong Wani. Jurnal Hutan dan Masyarakat, 9(2), 61-74. doi: 10.24259/jhm.v9i2.2861.

Persetyo, S.A., Romdhon, M.M. \& Badrudin, R. (2016). Kontribusi pendapatan usahatani padi sawah, itik petelur, dan ikan air tawar terhadap pendapatan total usahatani di Kabupaten Lebong. Jurnal Agrisep, 16(1), 91-100.

Pusari, D. \& Haryanti, S. (2014). Pemanenan getah karet (Hevea brasiliensis Muell. Arg) dan penentuan Kadar Karet Kering (KKK) dengan variasi temperatur pengovenan di PT Djambi Waras Jujuhan Kabupaten Bungo, Jambi. Jurnal Anatomi dan Fisiologi, 22(2), 64-74. doi: 10.14710/baf.v22i2.7819.

Santoso,T., Riniarti, M. \& Febryano, I.G. (2017). Identifikasi perubahan tutupan dan penggunaan lahan sebagai dasar penentuan strategi pengelolaan KPHP Way Terusan. EnviroScienteae, 13(3), 208-217.

Saipurrozi, M., Febryano, I. G., Kaskoyo, H. \& Wulandari, C. 2018. Uji coba program kemitraan kehutanan di Kesatuan Pengelolaan Hutan Unit XIV Gedong Wani, Provinsi Lampung. Jurnal Hutan Tropis, 6(1), 35-42.

Sarjono, A., Lahjie, A. M., Kristiningrum, R. \& Herdiyanto. (2017). Produksi kayu bulat dan nilai harapan lahan jabon (Anthocephalus cadamba) di PT Intraca Hutani Lestari. Jurnal Hutan Tropis, 5(1), 22-30.

Soekartawi. (1995). Analisis Usahatani. Jakarta: UI Press.

Susanti \& Rauf, R.A. (2013). Analisis faktor-faktor yang mempengaruhi pendapatan usahatani jagung manis. Jurnal Agrotekbis, 1(5), 500- 508.

Susilowati, S.H. dan Maulana, M. (2012). Luas lahan usahatani dan kesejahteraan petani. Jurnal Analisis Kebijakan Pertanian, 10(1), 17-30. 